\title{
SOBRE LA JUSTICIA EN LA ETAPA HISPÁNICA. EL CASO DE MARACAIBO
}

\author{
María Dolores Fuentes Bajo \\ Universidad de Cádiz.
}

\section{$\underline{R E S U M E N}$}

Recoge nuestro trabajo los primeros resultados de una investigación en curso acerca de Venezuela en el sigloXVIII, en concreto, sobre la administración de justicia en la provincia de Maracaibo. Se analizan las diversas demandas que se presentaban ante los tribunales, así como los tipos de transgresores que recogen las fuentes.

Palabras claves: Justicia, Iberoamérica, siglo XVIII.

\section{ABSTRACT}

Our work compiles the early results of an investigation in process about Venezuela in the $18^{\text {th }}$. Century', specially about the administration of justice in the province of Maracaibo. We analized the various claims that were submitted to court and the types of transgressors registered in this source.

Keywords: Justice, Latin America, XVIII't century.

\author{
Emprendi este artículo \\ mi padre, las incertidumbres del viaje azul. \\ Palabras y dolores inexorables \\ retrocesos y avances inulnerables.
}

Sigo rogando $P A Z$ donde se encuentre

Este trabajo se ocupa de la Venezuela colonial, para ser más exactos, de cuestiones relacionadas con la administración de justicia en el setecientos en Maracaibo, una gobernación situada en su vertiente occidental.

Como paso previo, querría subrayar que el análisis del tema propuesto entraña ciertas dificultades, una de ellas viene dada por las referencias en extremo concisas que se pueden rastrear en los archivos; en efecto, la mayoría de los sesenta procesos estudiados -fechados entre 1690 y 1820 - facilitan una información 
fragmentaria: son pocos (hasta la fecha) los expedientes voluminosos que hemos podido descubrir, son raros los casos a los que se puede hacer un seguimiento de principio a fin. Por otra parte, es notable la diversidad de demandas y de tipos humanos directa o indirectamente implicados, lo que en un estadio posterior de nuestra investigación, con toda seguridad, obligará a efectuar recortes, al ser una temática demasiado amplia. En otro orden de ideas, lo relativo a las autoridades con competencias en la materia, es dificil de sintetizar en pocas palabras, al estar presentes en nuestros documentos tanto jueces civiles como eclesiásticos, sin una delimitación clara de sus respectivas parcelas $y$, como es fácil deducir, con puntos de vista no siempre idénticos.

Por todas estas razones, mi objetivo se ciñe a exponer una serie de reflexiones, nunca conclusiones definitivas, que el tema sugiere, máxime cuando se trata de una investigación en curso. Mostraré un panorama general sobre la compleja administración de justicia en la colonia, con especial hincapié en Maracaibo. Se trata de una provincia de trayectoria problemática hasta casi el final del período hispánico, como el resto de lo que hoy llamamos Venezuela y que en la colonia no era más que una serie de gobernaciones sin nexo entre si ${ }^{1}$.

Entremos en materia, después de estas palabras preliminares.

\section{LOS TRANSGRESORES}

Aparecen relacionadas en nuestros expedientes judiciales muchas y diferentes personas, susceptibles de agrupar en una serie de apartados -siempre haciendo la salvedad del carácter provisional de esta primera clasificación por la naturaleza del trabajo que se presenta-. Así podríamos diferenciar cuatro grupos de transgresores que, casualmente, sólo engloban a personas hasta cierto punto acomodadas y pertenecientes a los segmentos de población más blanqueados.

El primero estaría formado por servidores de la Corona de variada condición, pues se reseñan oficiales de las Cajas Reales junto a gobernadores y tenientes. Citaríamos entre los primeros, nombres como el de Juay Igay o Juan Marrufo, si bien de las infracciones más graves serían autores Antonio Alguero, teniente de

' MORÓN, Guillermo, Breve historia de Venezuela. Madrid, Espasa-Calpe, S.A., 1979, pp.106ss.; LOMBARDI, John V., Venezuela. La bisqueda del orden. El sueño del progreso. Barcelona, Editorial Crítica, 1985, pp. 107ss.; ARELLANO MORENO, Antonio, Breve historia de Venezuela, 1492-1958. Caracas, Italgráfica, S.R.L., 1974, pp.72ss. 
Río Hacha, implicado en negocios de contrabando y, sobre todo, el gobernador Francisco Ugarte que llegó a ser depuesto por sus irregularidades².

Otro sector, relativamente bien documentado, es el de los eclesiásticos. De ellos diremos que en su totalidad pertenecían al clero diocesano y que los hay presbíteros -como Fernando Sanjust, que se mencionará en repetidas ocasiones en esta comunicación-, canónigos de la catedral -caso de Juan José Mendoza- y, también, vicarios de la iglesia de Maracaibo, como Alberto Soto que lo fue en los primeros años del siglo ilustrado?

Integrarían el tercer apartado militares. De Jaime Moreno disponemos, relativamente, de más datos. Así se conoce que fue primero ayudante $\mathrm{y}$, más tarde, capitán de la tropa fija de Maracaibo. De la documentación se desprende que fue hombre de cierta influencia, al gozar de las simpatías del gobernador de Maracaibo Salvador Muñoz que, según las sospechas más o menos justificadas de un obispo, le hacían merecedor de un trato más considerado por parte de los tribunales, saliendo bien parado de litigios ocasionados de su talante enamoradizo ${ }^{4}$

También en nuestra lista reseñamos comerciantes y dueños de barcos, que formarían el grupo cuarto.

Como nota curiosa, en los expedientes analizados hasta el momento los transgresores han sido siempre hombres, con excepción de una mujer. Se trata de Bárbara Villamil; pero hasta ahí llegan los datos de que disponemos. No sabemos si pertenecía a las capas más acomodadas de la población o todo lo contrario, a ciencia cierta. Podemos, eso sí, barajar alguna hipótesis sobre esta mujer, sin ánimo de que sea concluyente o definitiva. Así, el hecho de que durante bastante tiempo, casi 15 años, se valiera de diferentes recursos y estrategias para dilatar el juicio por el asesinato de un oficial de las Cajas Reales, hace sospechar que se

\footnotetext{
${ }^{2}$ Carta del gobemador al rey, de Maracaibo 4 de abril de 1708 (Archivo General de Indias de Sevilla, en adelante,AGI, Santa Fe 282); real despacho de 19 de febrero de 1709 (AGI, Santa Fe 282); real cédula al gobernador de Maracaibo, de 28 de julio de 1714 (AGI, Santa Fe 503); extracto de memorial de Francisco Ugarte, sin fecha (AGI, Caracas 31). De este último funcionario, Francisco Ugarte, hallamos una somera referencia en Guillermo Morón, Breve historia..., p. 113.

${ }^{3}$ Carta de Laureano Escaray, de Maracaibo 4 de abril de 1708 (AGI, Santa Fe 282); Autos obrados contra el presbítero Dn. Fernando José Sanjust y recurso de fuerza interpuesto por el teniente justicia mayor de Mérida Dn. Luis de Celis contra las providencias del provisor y vicario de dicha ciudad Dn. Luis Dionisio de Villamizar. 1788-1792 (AGI, Caracas 396); representación al rey del obispo Rafael Lasso de la Vega, de Maracaibo 5 de enero de 1820 (AGI, Caracas 958).

4 Oficio del obispo de Mérida-Maracaibo, fray Juan Ramos, al gobernador Dn. Salvador Mur̃oz, de Mérida 16 de agosto de 1786 (AGl, Caracas 958).
} 
trataba de una persona de posición relativamente desahogada y que se movía en determinados círculos de poder 5 .

\section{LAS TRANSGRESIONES}

Igualmente el término diversidad es el que mejor las define: las hay privativas de un solo grupo -como las pequeñas o grandes corruptelas que cometen los funcionarios en su gestión- 0 , bien, comunes a varios de ellos -caso del contrabando que como veremos es uno de los grandes problemas que encuentran las autoridades en Maracaibo y del que se benefician los más diversos sectores de la sociedad-. Las hay profusamente documentadas (el desacato de Sanjust al obispo ocupó un número nada despreciable de páginas), mientras que, por el contrario, otros delitos son conocidos por referencias breves e indirectas -del asesinato de Armesto Sotomayor desconocemos todo, las circunstancias en que se produjo y el nombre de la mayoría de los implicados-.

Por lo que se refiere a los oficiales del rey y a sus corruptelas, están documentados diferentes funcionarios que prestaban sus servicios en las Cajas Reales de Maracaibo que fueron censurados por irregularidades más o menos serias en su gestión. Las fuentes, de cualquier modo, no siempre son demasiado explícitas: del visitador Juan Marrufo y el tesorero Juan Igay se limitan a señalar que cometieron fraudes, mientras que en otros casos recogen la sanción recibida. En 1690, es un ejemplo, el gobernador se vio obligado a relevar a los oficiales reales y a disponer su prisión; tambiên vienen al caso las breves referencias documentales acerca del contador Francisco de Cenea o Zenea, depuesto igualmente en 1713. De José Armesto, tesorero de Maracaibo hacia 1759, estamos algo más informados pues extrajo, según todas las sospechas, en varias ocasiones, importantes sumas de las Cajas Reales (una vez, cerca de 4.000 pesos, en concreto 3.987 pesos, 4 reales), motivo por el que fue multado'.

Pero otro tipo de funcionarios también se vio envuelto en litigios; los pleitos recogen, en este sentido, la presencia de algunos gobernadores de Maracaibo; las más de las veces se trata de un mero trámite ligado al cargo, ya que al finalizar

\footnotetext{
" Carta número 28 del gobernador de Maracaibo, Francisco de Santa Cruz, a José de Gálvez, de Maracaibo 24 de julio de 1778 (AGI, Caracas 31).

${ }^{5}$ Tres reqles cédulas al gobernador, a los oficiales reales y al obispo de Caracas de la misma fecha, 6 de abril de 1690 (AGI, Santa Fe 503); real despacho de 16 de febreto de 1709 a la Audiencja de Sante Fe (AGI, Santa Fe 282); real despacho de 28 de julio de 1713 (AGI, Santa Fe 282); real cédula al cabildo secular de Maracaibo, de 28 de julio de 1713 (AGI, Santa Fe 503); dos reales cédulas a la Audiencia de Santa Fe y al gobernador de Maracaibo de 28 de julio de 1714 (AGI, Santa Fe 503); representación de José Armesto de Sotomayor, de Maracaibo 18 de octubre de 1759 (AGI, Caracas 31).
} 
su mandato debían rendir necesariamente cuentas en un juicio de residencia, en donde tenían oportunidad de presentar sus quejas todos aquellos individuos que se consideraran agraviados; no obstante, aparecen casos en que fueron objeto de acusaciones, en un contexto y en unas circunstancias bien distintas: fue lo ocurrido, por ejemplo, al gobemador Francisco Ugarte, en los años centrales del siglo XVIII, que se convirtió en víctima del funcionario que le sustituyó, suponiéndole había echado mano de dineros públicos en beneficio de su persona, entre otras actuaciones delictivas. Francisco Javier Moreno presentó contra Ugarte denuncias relacionadas con la mejora y reconstrucción emprendida de diferentes edificaciones en la ciudad de Maracaibo, sospechando que se habían financiado de forma irregular; se trataba de la casa de los gobernadores y de la sede de la Compañia de Caracas. ${ }^{?}$

Mención aparte merece todo lo relacionado con lo que en el lenguaje de la época se denomina comercio ilicito. Individuos pertenecientes a las más diferentes profesiones y quehaceres fueron relacionados con este delito. Se registran, en este sentido, tenientes de gobernador que estuvieron implicados en el tráfico ilicito de mercancías por la zona o, al menos, consintieron en que tal comercio tuviera lugar en sus respectivas jurisdicciones.

En 1708, sin ir más lejos, denunciaba el gobernador Laureano Escaray que el teniente de Río Hacha, Antonio Alguero, daba protección a determinados comerciantes de Curazao y facilitaba la distribución ilegal de sus mercancías por la zona. Y proseguía en sus denuncias, pues sus intentos por reprimir el contrabando en Maracaibo habían provocado tal descontento que los vecinos de la ciudad, literalmente, se habían levantado contra su autoridad; pero lo que era a su entender más grave e incomprensible era que habían participado sacerdotes, entre ellos el mismo vicario de la iglesia de Maracaibo, Alberto Soto ${ }^{8}$. Y es que el problema del contrabando era muy grave en una provincia como Venezuela, alejada de las rutas de flotas y galeones. El mismo Escaray lo dejaba patente al afirmar que si se privara a los habitantes de Maracaibo del

..."comercio que tienen con Curazao, no obedecen las órdenes del gobernador ni conocen a Su Majestad por rey de Castilla"."

\footnotetext{
1 Extracto del memorial de Francisco Ugarte, sin fecha; dos reales ordenes al duque de Alba, de Buen Retiro 21 de agosto de 1759 y 16 de junio de 1760; solicitud de Ugarte, sin fecha; real orden al marqués de San Juan de Piedras Albas, de Buen Retiro 18 de enero de 1764. Todos estos documentos en AGI, Caracas 31.

" Carta del gobernador al rey, de Maracaibo 4 de abril de 1708 (AGI, Santa Fe 282). En nuestras fuentes figuran otros registros que relacionan a eclesiásticos con el comercio ilícito, así un despacho de 19 do febrero de 1691 daba cuenta de haber comprado negros ciertos eclesiásticos de Río Hacha a un navio holandés (AGI, Santa Fe 503).

${ }^{9}$ Carta del gobernador al rey, de Maracaibo 4 de abril de 1708 (AGI, Santa Fe 282).
} 
Con independencia de que fueran exageradas o no las expresiones de Escaray, lo cierto es que en los tribunales abundaban los pleitos por este delito. Como muestra, podemos citar el que sigue, que tiene como protagonistas a dos soldados: el teniente de guardamarina Mariano Cangas y el cabo Juan Acedo; de su causa se sabe, en concreto, que guarda relación con la apropiación de mercancía de contrabando en beneficio propio, en el cabo de Oriboro, y la liberación de los tripulantes de la goleta que la transportaba ${ }^{10}$.

Queda hacer una referencia, para concluir este punto, a comerciantes y dueños de barcos. Con frecuencia aparecen censurados por la autoridades por comprar y vender determinados artículos de procedencia dudosa; no aporta muchos datos acerca de sus personas la información disponible ${ }^{11}$, al fijarse preferentemente en las mercancías que eran objeto de su interés, los lugares en los que este tráfico era más intenso ${ }^{12} \mathrm{o}$ las penas a que fueron condenados por sus actividades delictivas -multas y expropiaciones se documentan con frecuencia ${ }^{13}$.

Otro grupo de transgresiones serían de naturaleza bien distinta. Sirva de ejemplo la causa seguida al presbítero Fernando Sanjust, a mediados de los 80 del siglo XVIII, originada por desacatar las disposiciones de su superior. Si bien guardan más relación estos papeles con el funcionamiento interno de la diócesis de Mérida-Maracaibo, recién creada por aquellas fechas, que con una auténtica transgresión a la norma establecida, los acontecimientos terminarán desbordándose hasta extremos inusitados. En el origen del problema está la rigurosa política del primer obispo, fray Juan Ramos de Lora, en orden a disponer de un clero disciplinado y obediente. Sabemos que Lora ocupó la diócesis desde 1784 hasta, aproximadamente, 1791, año de su muerte; se vio en la ingrata tarea de organizar

\footnotetext{
"Real orden a Antonjo Ventura de Taranco, de Palacio 5 de enero de 1780 (AGI, Caracas 31).

" De algunos, solo el nombre, prácticamente; es lo que ocurre con Bernardo Guilién y su mujer, a quienes se siguió autos por ilícito comercio en 1718, como se reseña en una carta del gobernador de Maracaibo de 8 de abril de ese año (AGI, Santa Fe 282); lo mismo se puede decil de Antonio Medina (real orden al marqués de San Juan de Piedras Albas, de San Ildefonso 17 de agosto de 1764. AGI, Caracas 31); de Francisco José Morales se puntualiza algo más; que era reincidente (oficio de remisión de una carta del gobernador de Maracaibo al Consejo de Indias, de 28 de mayo de 1779 (AGI, Caracas 31).

:2 De Manuel de Velarde, se reseña por ejemplo en nuestras fuentes que fue sorprendido en los puertos de Altagracia (real orden a Antonio Ventura de Taranco, de San Ildefonso 26 de septiembre de 1786. AGI, Caracas 31).

${ }^{9}$ A Francisco Nieto le fue confiscada su goleta en 1764 (real orden al marqués de San Juan de Piedras Albas, de Palacio 12 de diciembre de 1764. AGI, Caracas 31). Pueden consultarse sobre la materia las obras de Ramón AIZPURUA (Cirazao y la costa de Caracas. Introducción a la historia del contrabando de la provincia de Venezuela en tiempos de la Compañia Guipuzcoana, 1730-1780. Caracas, Biblioteca de la Academia Nacional de la Historia, núm. 222. Fuentes para la Historia colonial de Venezuela, 1993) y Celestino Andrés ARAUZ MONFANTE (El contrabando holardés en el Caribe durante la primera mitad del siglo XVIII. Caracas, Biblioteca de la Academia Nacional de la Historia, núm. 169. Fuentes para la Historia Colonial de Venezuela, 1984, 2 vols.).
} 
y, casi seguro, domesticar a los eclesiásticos de la zona, hasta la fecha dependientes del diocesano de Caracas, y que habían gozado de una total autonomía, por la considerable distancia existente.

Para ello no dudará en arbitrar severísimas medidas correctivas -la misma reclusión de los sacerdotes remisos a sus mandatos figura entre ellas- lo que propiciará en algún caso actitudes levantiscas, en determinados círculos de clérigos descontentos. El presbítero Fernando Sanjust, que se negó a trasladarse a su curato, mostraría su disconformidad de palabra y de obra, lo que le acarreó que fuera confinado en el hospital de Mérida, donde existían unos cuartos habilitados para este fin. Sin embargo, si damos crédito a las declaraciones de ciertos testigos, el castigo del obispo no tuvo el efecto deseado: presionaba al carcelero, a veces con cierta violencia -en una ocasión, al menos, le gritó y le dio un pescozón-, para que le franqueara la salida del hospital cuando se le antojaba y no desperdiciaba ocasión para desacreditar al diocesano, al menos es lo que afirmaba el testigo Tomás Varela:

“... que cuando le ha llegado a llevar algín recado de su Señoria Ilustrísima ha hecho burla y dicho que se ensucia en su Señoria Ilustrísima..."."

Todos estos problemas se agravaron con la mediación de las autoridades civiles de Mérida -ya se verá con detalle en otro lugar este punto- que no consiguió sino radicalizar la postura del diocesano, dispuesto a utilizar todos los recursos disponibles, aunque para ello se granjeara la enemistad de los representantes de la Corona, que también se verán salpicados por su celo disciplinario.

Pero lo de Sanjust no fue un caso aislado; en el mismo contexto, otros sacerdotes se vieron en dificultades. Baltasar Rodríguez tampoco aceptó los planes del obispo para el clero secular ni su política de redistribuirlos por toda la gobernación. Como Sanjust, se negó rotundamente a ejercer su labor apostólica en un lugar perdido (el pueblo de Ziruma, en este caso) y no desperdició ocasión para proferir "expresiones de irrespeto" contra el diocesano. Del presbítero Francisco Villamil sabemos que su "genio precipitado" motivó que fuera procesado por el obispo, lo que le impulsó a pasar a Maracaibo y, más tarde, a Caracas, razón por la cual fue perseguido por desertor. De Gabriel Salón -o Salom-, el último ejemplo que vamos a citar, se reseñan sus intenciones de trasladarse a Europa, tras ser suspendido por fray Juan Ramos de Lora's.

\footnotetext{
14 La declaración del tonsurado Varela tiene fecha de Mérida 4 de octubre de 1788 (AGI, Caracas 396).

is Representación del obispo de Mërida-Maracaibo al monarca, de 20 de marzo de 1790 (AGI, Caracas 396).
} 
Otros eclesiásticos, no obstante se vieron en dificultades con la justicia por razones bien distintas: el canónigo magistral Juan José Mendoza, sin ir más lejos, a causa de su credo político y compromiso con la causa de la independencia, hasta el punto de cambiar su cómodo destino en la catedral por el campo de batalla y, más tarde, por el exilio, cuando las victorias de las tropas realistas obligaron momentáneamente a los revolucionarios a desperdigarse.

Sus profundas convicciones le empujaron a desempeñar un papel nada despreciable en aquellos años. En su juramento de la independencia quiso dejar bien patente la firmeza de sus ideas con la mayor rotundidad:

..."añadió dicho magistral a la fórmula con que lo tomaron los disidentes... estas palabras; $y$ de no reconocer a Fernando Séptimo aún cuando vuelva a su trono...". 16

Los testimonios documentan asimismo ${ }^{17}$ que fue capellán de una expedición que desde Barinas dirigieron los insurgentes contra Mérida y Trujillo; igualmente reseñan que sufrió prisión, a la altura de 1812, y que, algo después, buscó refugio en las Antillas francesas, junto a otros patriotas ${ }^{18}$.

Otra transgresión recogida en nuestros documentos es el incumplimiento de palabra esponsalicia; por esta razón, Bárbara Sánchez interpuso demanda al ayudante de la tropa Jaime Moreno. Este litigio sirvió de excusa de nuevo al obispo de la diócesis Ramos Lora para mostrar su faceta más combativa; en este caso medirá sus fuerzas con el gobernador de Maracaibo Salvador Muñoz con el pretexto de que no le prestaba suficiente apoyo para forzar a Moreno a contraer nup-

\footnotetext{
${ }^{16}$ Declaración de Martín de Soto, de 13 de febrero de 1819 (AGI, Caracas 958).

${ }^{17}$ Declaración de José de la Cruz Olivares, de 13 de febrero de 1819 (AGI, Caracas 958). BRICEÑO PEROZO, Mario, "Las causas de infidencia", en LÓPEZ BOHÓRQUEZ, A. E., (ed.) La Real Audiencia de Caracas en la historiografia venezolana (materiales para su estudio). Caracas, Biblioteca de la Academia Nacional dela Historia. Fuentes para la historia colonial de Venezuela, 1986), p. 293, incluye a Juan José Mendoza en la lista de sacerdotes que fueron procesados por infidencia en la Audiencia de Caracas, Véase, igualmente PÉREZ VILA, Manuel "El clero en la independencia de Venezuela". Boletín de la Academia Nacional de la Historia. Caracas, núm. 157, Caracas, chero-marzo de 1957, pp. 36ss.

${ }^{18}$ Unos 30 años después de su accidentado paso por el hospital de Mérida, reaparece en los documentos Fernando Sanjust, que es uno de los funcionarios eclesiásticos que intervino en el proceso incoado al canónigo magistral J.J. Mendoza. Tal vez porque habia dejado de ser un clérigo indisciplinado, tal vez porque, tras la muerte del obispo Lora, las aguas habían vuel to a su cauce, y los antiguos perseguidos habian recuperado parte de sus prebendas. Representación del promotor fiscal Fernando Sanjust, de Maracaibo 15 de febrero de 1819 (AGI, Caracas 958).
} 
$\operatorname{cias}^{19} \mathrm{y}$ concluir, de este modo, una causa matrimonial que se alargaba ya algunos años ${ }^{20}$.

Para concluir este epígrafe de muchas y diversas transgresiones de la ley, una escueta alusión al único caso de homicidio existente. Ya se mencionó la falta de datos sobre la muerte violenta del oficial de las Cajas Reales Armesto y que entre los inculpados se encontraba, Bárbara Villamil, la única fémina que reseñan los expedientes ${ }^{2 !}$.

\section{LOS JUECES Y LA JUSTICIA}

Creo de interés destacar la existencia de una serie de factores que resultarán claves para comprender la limitada operatividad de la administración de la justicia.

La dificil coordinación entre los mismos jueces, sería uno de ellos. Cabe en este sentido recordar las diferencias que tuvieron entre sí algunos gobernadores de Maracaibo (caso de Francisco Ugarte y sus sustituto, Francisco Javier Moreno) que determinó a la Corona a mediar en el conflicto; dispuso, entre otras medidas, el retorno a la península del funcionario saliente, a pesar de que determinados trá-

\footnotetext{
${ }^{19}$ Auto acordado de la Audiencia de Santo Domingo, de Santo Domingo 27 de junio de 1785; representación del obispo fray Juan Ramos al gobernador Salvador Muñoz, de Mérida 16 de agosto de 1786; auto del provisor del obispado, de Maracaibo 23 de septiembre de 1786; dos representaciones del obispo al marqués de Sonora, de Mérida 14 de octuble y 15 de noviembre de 1786; otra representación del diocesano a Antonio Porlier, de Mérida 21 de marzo de 1789. Todos estos documentos en AGI, Caracas 958. Dos reales cédulas al gobernador de Maracaibo, de Madrid 16 de diciembre de 1789 y 15 de diciembre de 1792. Ambas en AGI, Caracas 396.

21" RIPODAS ARDANAZ, Daisy, El matrimonio en Indias, realidad social y regulación juridica. Buenos Aires, Fundación para la educación, la ciencia y la cultura. 1977, pp. 63ss. Sobre los pleitos familiares y matrimoniales pueden consultarse los trabajos de BISTUE, N. C. y MARIGLIANO, C, "Los disensos matrimoniales en la Mendoza virreinal 1778-1810". Revista de Historia del Derecho núm. 20. Instituto de Investigaciones de Historia del Derecho. Buenos Aires 1992, pp. 75-101, KLUGER, V. "Los alimentos entre cónyuges; Los deberes y derechos paternofiliales a través de los juicios de disenso. Virreinato del Río de la Plata, 1785-1812"; "Algunas particularidades de los pleitos familiares en el virreinato de! Río de la Plata, 1785-1812". Estos tres artículos están publicados en la Revista de Historia del Derecho -núms. 18, 25 y 27; pp. 183-213, 365-390 y 219-245-. Instituto de Investigaciones de Historia de Derecho. Buenos Aires 1990, 1997 y 1999) y FUENTES BAJO, M. D. "Amor y desamor en la Venezuela hispánica: Caracas, 1701-1791". Boletín de la Academia Nacional de la Historia, Tomo LXXV, n² 298, Caracas abril-junio de 1992, pp. 49-62.

"Carta número 28 del gobernador de Maracaibo, Francisco de Santa Cruz, a José de Galvez, de Maracaibo 24 de julio de 1778 (AGI, Caracas 31) Teresa LOZANO ARMENDARES, en su estudio sobre México La criminalidad en la ciudad de México, 1800-1821. México, Universidad Nacional Autónoma de México, 1987, pp. 43ss, llega a unas valoraciones bien distintas sobre transgresiones y transgresores.
} 
mites aún no habían concluido, consciente de que su proximidad era un eterno motivo de discordia ${ }^{22}$.

La no siempre fluida relación entre las diferentes instancias judiciales es otro punto a tener en cuenta en el tema que nos ocupa. Son varios los ejemplos relativos a la falta de acuerdo entre las autoridades de Maracaibo y la Audiencia, tribunal superior al que se dirigieron las apelaciones; unas veces los recursos se presentaron a la Audiencia que tenía su sede en Santo Domingo, mientras otras se registran en la Audiencia de Santa Fe de Bogotá; en los dos casos, se trataba de tribunales muy alejados de la gobernación de Maracaibo ${ }^{23}$. Tenemos referencias acerca del descontento que experimentaban los gobernadores con los criterios y pareceres de estas Audiencias, fundamentados sobre presupuestos algo diferentes, al ser independientes de los intereses locales, lo que les llevaba a sostener posturas más flexibles, para desesperación de muchos ${ }^{24}$.

La pluralidad y diversidad de autoridades supuso, a veces, un lastre importante. Si la administración de justicia podía topar con ciertos escollos por la escasa colaboración entre los magistrados, el panorama se tornaba más enrarecido cuando por algún motivo se entraba en colisión con las autoridades eclesiásticas.

Las Leyes de Indias les reconocían ciertas materias de su competencia y fijaban una serie de mecanismos con el fin de facilitarles la realización de su labor; era necesario para ello cierto entendimiento con los funcionarios del rey -es decir, en el lenguaje de la época, disponer del "amparo real"- que se convertirían en el brazo ejecutor de las decisiones suyas. Sin embargo, las fuentes señalan, con relativa frecuencia, que se produjeron roces por este motivo, ya que la esperada colaboración entre una parte y otra no tenía siempre lugar en los términos que era de esperars.

\footnotetext{
${ }^{22}$ En efecto, el juicio de residencia del primero aún no se había celebrado. Véase: memorial de Francisco Ugarte. Sin fecha, en torno a 1759 ó 1760; dos reales ordenes al duque de Alba, de Buen Retiro 21 de agosto de 1759 y 16 de junio de 1760; solicitud del coronel Francisco Ugarte. Sin fecha, de 1764; real orden al marqués de San Juan de Piedras Albas, de Buen Retiro 18 de enero de 1764. Estos documentos en AGI, Caracas 31 .

${ }^{23}$ Desde 1786, se apeló directamente a la nueva Audiencia de Caracas, coincidiendo con su creación. Se pueden consultar dos obras de Ali Enrique López Bohorquez. La primera, ya citada con anterioridad (La Real Audiencia de Caracas en la historiografia...,), que recoge colaboraciones de diferentes autores sobre este tema, y Los ministros de la Audiencia de Caracas (1786-1810). Caracas, Biblioteca de la Academia Nacional de la Historia n 174. 1984, pp. 59ss.

${ }^{24}$ Carta del gobernador Laureano Escaray al monarca, de Maracaibo 4 de abril de 1708 (AGI, Santa Fe 282).

${ }^{25}$ Real cédula de 11 de abril de 1695 (AGL, Santa Fe 282); solicitud del coronel Francisco Ugarte. Sin fecha, de 1764 (AGI, Caracas 31)
} 
Los resortes al servicio de la administración de la justicia podian ser un arma de doble filo. Se ha hecho mención del "real amparo", otras veces nombrado "real auxilio", instrumento utilizado por la monarquía en las causas seguidas en los tribunales eclesiásticos; está documentado, sin embargo, que su cometido era más amplio.

En efecto, del respaldo de las autoridades civiles podían beneficiarse igualmente los acusados -apoyándose en el recurso que les brindaba la propia ley, siempre y cuando se dieran una serie de circunstancias. De esta suerte, si los acusados consideraban sus derechos seriamente lesionados, quedaban en suspenso todas las medidas dictadas por los tribunales y se les abría la posibilidad de acudir a una autoridad superior ${ }^{6}$-. En el mencionado expediente de Sanjust, el presbítero solicitó el amparo real del justicia de Mérida, alegando que

... se le habia "comunicado por el señor provisor en su auto a fin de introducirme en el cepo sin conocer el delito que ordene tan agrio mandamiento, de que supliqué con los últimos esfuerzos de mi obediencia por la incompetente e ignominiosa prisión, respecto de mi carácter y estado sacerdotal y, sin embargo en este rendimiento y súplica, se me compele segunda vez al cumplimiento de la misma prisión... y porque temo justamente el más crudo e ignominioso vejamen, para evitarlo me acojo según la real inmunidad de la real cédula de la fuerza al patrocinio de ella...para que su merced se sirva reconvenir con la real provisión ordinaria del asunto a su señoría el señor provisor a fin de que me dé testimonio de lo obrado para ocurrir a la Real Audiencia del distrito a fin de que me oiga las excepciones contra dicho auto que solo se encamina a vejarme sin mérito..." ${ }^{\prime 27}$.

En casos como éste las consecuencias derivadas de la mediación de los representantes de la Corona fueron imprevisibles: el obispo Ramos Lora y su provisor llegaron a la ruptura total con los gobernantes de Mérida, hasta el punto de excomulgar al justicia Luis Gutierrez de Celis ${ }^{28}$.

En otros casos, si bien es cierto que no se llegó a respuestas tan contundentes, la crisis se planteó en términos similares. En la demanda de esponsales con-

\footnotetext{
${ }^{20}$ Según precisaba el juez provisor Luis Dionisio de Villamizar, les reconocia esta prerrogativa la "real provisión de las fuerzas" librada por la Audiencia de Santo Domingo "en tiempo que regía esta provincia"; idéntico contenido tenían una real cédula de 27 de agosto de 1747 , así como la Ley 36 , Título $5^{\circ}$, Libro $2^{\circ}$ de la Recopilación de Castilla (despacho de 15 de octubre de 1788. AGI, Caracas 396), "2 Petición de Fernando Sanjust al teniente justicia mayor. Sin fecha, anterior al 4 de octubre de I788 (AGI, Caracas 396).

${ }^{2 x}$ Carta del gobernador Joaquín Primo de Rivera al rey, de Maracaibo 17 de noviembre de 1788 (AGI, Caracas 396).
} 
tra Jaime Moreno, la sangre no llegó al rí, quizá porque el obispo Lora no gustaba de tener al mismo tiempo abiertos diferentes frentes, quizá porque Moreno parecía gozar de aliados influyentes y temía, con razón, que el resultado de sus presiones no fuera de su agrado:

..."En vista de esto y de conocer palpablemente por los infundados recursos interpuestos que todos han sido puros efugios para eludir las disposiciones justísimas del tribunal eclesiástico, que en muchas ocasiones apenas ha sido un mero ejecutor de lo ordenado por la Real Audiencia, he querido con todo proceder con la mayor prudencia y tolerancia, tanto para evitar providencias algo más fuertes de que se podría valer mi ordinaria jurisdicción, como por no dar margen a que si llegaba a favorecer el gobierno al dicho teniente Dn. Jaime, por las recomendaciones que es manifiesto le han dispensado algunos superiores, quedasen desunidas la autoridad civil y eclesiástica..."?

Lo que no le impidió dirigir sus quejas a diferentes instancias ${ }^{30}$

El "amparo real", concebido en el papel como un medio para ganar flexibilidad y eficacia, en la práctica no siempre consiguió el efecto deseado; cierto es que vigiló que las autoridades no se extralimitaran en sus atribuciones pero no es menos verdad que a veces solo propició polémicas vacías de contenido entre los poderosos, celosos por defender sus respectivas parcelas de influencia ${ }^{3 !}$.

En otro tipo de pleitos, donde no tenían competencia tribunales eclesiásticos, se reconocía a los acusados ciertos derechos que les permitían la posibilidad de recusar a sus jueces, en determinados supuestos. En el juicio seguido a nueve personas por el asesinato del oficial real Armesto Sotomayor se documenta que tuvieron oportunidad, en repetidas ocasiones, de hacer uso de esta prerrogativa. Sin embargo, a veces (no puedo precisar si muchas o pocas), los resultados fueron distintos a los esperados; así los reos usaban y abusaban de estos mecanismos, prolongando por meses, cuando no por años, sus respectivos procesos. El ejemplo más claro de lo que decimos, aunque no el único, puede ser el juicio por la muerte de Armesto que se alargó cerca de 15 años-de 1768 a 1781 -y solo logró poner-

\footnotetext{
2" Oficio del obispo de Mérida-Maracaibo al gobernador Salvador Muñoz, de Mérida 16 de agosto de [786 (AGI, Caracas 958).

10 Dos representaciones del obispo al marqués de la Sonora y a Antonio Porlier, de Mérida 18 de noviembre de 1786 y 21 de marzo de 1789 , respectivamente (AGI, Caracas 958).

"Subyace en esta pugna, la presión de los tribunales eclesiásticos por recuperar parte de sus prebendas, reivindicación que les resultará dificil cuando no imposible al estar marcado el siglo XVIII por el signo de una creciente secularización. Veáse, SANCHEZ BELLA, l., Iglesia y estado en la América española. Pamplona, Ediciones Universidad de Navarra. 1990, pp. 207ss; TOMÁS Y VALIENTE, F., El derecho penal de la monarquía absoluta (siglos XVI, XVII, XVIII). Madrid, Editorial Tecnos, 1969, pp. 93ss.
} 
le término la decisión de las autoridades de hacer oidos sordos a los alegatos inútiles suscritos por los encausados para poder obtener una sentencia definitiva ${ }^{32}$.

\section{CONCLUYENDO}

Es difícil, dado el carácter de nuestra investigación, llegar a valoraciones definitivas.

Se han analizado las demandas que se presentaban ante los tribunales, subrayando su diversidad y originalidad. También se ha ofrecido una primera clasificación de los transgresores que registran los expedientes, aunque a la fuerza está incompleta.

Ha tenido ocasión de apreciarse, en último lugar, la compleja administración colonial y, en concreto, los mecanismos destinados a agilizar -a veces, entorpecer- la justicia. Unos mecanismos, unos resortes, concebidos por la Corona para poder gobernar con equidad en unas tierras demasiado distantes de la península y a través de unos funcionarios que podrían ejercer un poder sin límites, caso de no existir los contrapesos adecuados. Se han analizado situaciones de crisis, de ruptura casi total entre oficiales de la Corona y ministros de la Iglesia, y eso no es casual o episódico, ya que es la misma monarquía la primera interesada en que unas autoridades vigilen a otras, aunque se pueda llegar a situaciones de indudable tensión, a cambio de asegurar una mejor gobernabilidad.

\footnotetext{
12 Carta de Francisco de Santa Cruz a José de Gálvez, de Maracaibo 24 de marzo de 1778; real orden a Antonio Ventura de Taranco, de Aranjuez 3 de mayo de 1781. Ambos documentos en AGI, Caracas 31. Como apunta Eduardo Martiré ("El recurso de apelación contra las decisiones del virrey o presidente de las Audiencias de Indias a fines de la época hispánica, 1806". VI Congreso del Insituto Internacional de Historia del Derecho Indiano. Instituto de Cooperación Iberoamericana. Seminario Americanista de la Universidad de Valladolid 1984, pp. 341-359), fue la misma Corona la que respaldó los recursos como forma de velar por una mejor administración de justicia en unas provincias tan alejadas como las americanas.
} 